\section{EUGENICS IN RELATION TO PUBLIC HEALTH.}

BY

Willtam J. Howarth, C.B.E., M.D., Medical Officer of Health, City of London.

It is now generally established that the problems included in the study of Eugenics are more or less intimately associated with those of preventive medicine. If proof be necessary to establish the validity of this contention, it is to be found in the recently published Memorandum of Sir George Newman. This document, which is a statemanlike exposition of public health ideals, and which for many years will be extensively quoted in support of any forward movement, outlines the provisional articles of a national policy of Preventive Medicine. First place is given to the science of Eugenics and the principles of sound breeding. Already, the study of the new science had been advocated as one of the additional subjects which ought to be included in the medical curriculum. In view of this lead, it seems desirable that some time might profitably be devoted to the consideration of how we; as Medical Officers of Health, can most usefully promote progress in this particular connection.

The science of Eugenics was defined by Galton as "the study of those agencies under social control which may improve or inpair the racial qualities of future generations either physically or mentally." The agencies which have come under consideration since that definition was framed are so numerous, and many are of so controversial a character, that a general paper cannot be expected to deal in a comprehensive manner with all the various issues. I shall therefore content myself with summarising some of the points which have mainly appealed to me.

Some hold that the practical application of the principles of Eugenics may result in a country attaining an advanced place in commerce and warfare and even contend that this would be a sufficiently elevating ideal; but to a Medical Officer of Health, Dr. Edgar Schuster's suggestion to regard it "as a road to increased happiness; or at any rate as a means of preventing much unnecessary suffer- ing," seems a more inviting standpoint. It would perhaps be accepted that a population in which the principles of sound breeding had been observed would be happier and less liable to unnecessary suffering than one in which negligence had to be recorded, but until these principles can be adequately defined so as to be understood and appreciated by the mass of the population, progress will not be rapid. It is therefore probable that the verbal extension of Eugenics, in the Memorandumquoted, is suggestive of the more important results of an advanced practice of Eugenics rather than the idea that breeding on sound lines may be made immediately operative.

In all our daily work, we, Medical Officers of Health, are mainly concerned in diminishing the amount of human suffering and in prolonging the period of human activity. To this extent, and no matter by what methods we arrive at that result, we are practically eugenists; but consideration of some of the fundamentals has stimulated enquiry as to whether our efforts are wholly free from certain disadvantages, possibly to the extent that some of the means we propose, advocate, or practise, are actually opposed to the end we desire. We must admit that part of our activities are those of the opportunist, since they only ameliorate the lot of those who pass their lives contemporaneously with us. Such methods are productive of the minimum of permanent advantage to future generations and are thus dearly purchased; but it is a much more important criticism if it can be proved that any of our proposais, studied in the light of Eugenics, are so unsound that they may actually be dysgenic in effect.

The fundamentals of the science establish the contention that we are what we are as a result of two causes,-inborn potentialities, and the effect of environment on the development of these potentialities. It is assumed that when an individual is born, he is at that time endowet with all the powers which he may be ultimately capable of developing. It seems obvious that each factor is dependent in varying degree on the other; for without satisfactory environment, inborn potentialities may fail to develop their highest possibilities; and likewise the best of "nurture" without 
satisfactory "nature" would fail to produce acceptable results. The nature of a child, however, is assumed to be dependent upon his ancestry, and only qualities possessed by one or more of his ancestors are handed down. What qualities are transmissible, the extent to which they are transmissible; and the mechanism of transmission, are unknown factors, as also are the results of interaction of different qualities. If we combine with these difficulties the position that each child generally receives its inborn characters from two parents of non-associated lineage, the impossibility of comprehensively setting out the inborn qualities which any child of known parentage may be expected to display, will be recognised. It is obvious that this science of Eugenics opens to our imagination vast possibilities for the improvement of the human race. In certain instances sufficiently sound knowledge has been acquired on which positive recommendations may be based, even if these are at present of a somewhat tentative character, but in others the real fundamentals have not yet been so sorted and arranged that they justify the recommendations of a definite policy.

Although eugenics draws extensively on related scientific hypotheses and conclusions to establish the positions which it lays down, the question of heredity, and the relationship of nature and nurture, and the exact bearing of the mass of sociological information which is antually accumulating to prove or disprove rival theories, are of greatest interest to the Medical Officer of Health

Such questions as the effect of environment on the germ-plasm do not come divectly within the scope of our work except perhaps so far as we can obtain information which may be of service to those working in this field of research. We are limited to an appreciation of such work, and a consideration of how far accepted results affect our methods..... Examples of matters of interest, however, are whether the germ-plasm of an alcoholic may be affected by his vice, and if so, whether the alteration may be a quality transmissible to his progeny. Other racial poisons, such as syphilis, have a like importance.

The Mendelian principtés have alsó a gripping influence, but this subject is now becoming so complex, and so many exceptions have been discovered, that the attractiveness of simplicity which this branch of scientific work seemed to present has now almost disappeared, and here again, our chief duty seems to be in the direction of collecting facts. In the present state of knowledge, Mendelism rules can hardly be applied to human problems as they concern us; Davenport attempted to prove that mental deficiency is a Mendelian recessive character, and thereon to suggest that "it is possible to give definite advice to those about to marry or who do not wish to transmit their undesirable traits," and continues "weakness in any trait should marry strength in that trait and strength may marry weakness." Dr. Heron has submitted this work and that of Dr. Weeks to critical examination, and writes "above all we repudiate in the name of Eugenics any sanction for the enfeeblement of strong stocks by mating them with weak stocks on the basis of a theory which, even if true, declares that all the off-spring will carry latent defect." A reply to the criticism has been issued and the whole subject is worth consideration, but to medical officers of health the possibility of mental deficiency being accounted for on Mendelian lines is a matter of minor importance; it may or may not be the fact; the position, that forms of mental deficiency are hereditarily transmissible, is the important circumstance.

A knowledge of the principles of evolution, whether Lamarckian or Darwinian, cannot be regarded as superfluous, and, as the subject is of importance to the understanding of heredity; the Medical Officer of Health and his colleagues should assist by recording facts. As a matter of practice, and in view of the fact that we are unable definitely to select the fit from the unfit; he should, no matter what policy of a negative character may appear desirable; endeavour, as far as may be practicable, and by whatever means may be available, to ensure that all individuals whom he may think worthy of preservation shall be given every chance of complete development; though the ideal would be to secure the survival of the fittest among those best fitted to survive.

The difficulty of accurately prognosticating the qualities with which any child of known 
parentage may be endowed have been mentioned; but as a positive assumption we may definitely assert that a child may be expected as more likely to possess a certain quality if both the parents possess that quality than one in whose parents these qualities are lacking or deficient. Complications are introduced if environment can so act on the mother of an unborn child that the potentialities of which that child should be born possessed are interfered with, or if after birth environment can affect the development of the powers with which it is actually born.

Professor Karl Pearson sums up the practical situation when he writes "there is no more important problem before both eugenist and medical officer than whether man is the product of his environment, or the environment the product of the man."

Certain examples will help to illustrate these points and the problem of tuberculosis is perhaps one of the best suited to this purpose. Since the discovery of the tubercle bacillus, the hereditary transmission of the disease has come to be accepted as an occurrence of rarity, and the theory of transmission of an indefinable tendency or liability to attack, replaces it. Since most people show signs of having been attacked at some time or other, is survival due to inherited resistance or: to variation in the attacking organism or both? Is the pre war curve of decline, which is based upon recorded deaths, an indication of real dimunition of prevalence; and if. so, are preventive measures in the main the responsible agents, or is it due to a gradually acquired power of resistance? Is the increase observed during the War due to conditions created by the War; to the fact of the increased employment of women - who may be more susceptible than man; or to the fact that women as a consequence of occupation have been placed in greater numbersin positions whereattack was more probable; or is it because more persons of poorer physique have been employed whilst their better constitutedfellows have been away? Why do patients in asylums under good conditions succumb to the disease in greaten numbers than attendants, doctors, and nurses? Why is the correlation between parents less than between parents and children?. And again, tuberculosis is often found in association with bad sanitation; how much is due to inherent tendency to attack, and how much to environment? Is there something lacking in the residents of insanitary areas such as inability to compete successfully with their fellowmen in the race of life, or is there some other deficiency of a personal character which results in theirdrifting in to the worst place because they cannot afford the better, and there to become enfeebled; or is it because the attack results in enfeeblement, and being impoverished, these persons seek final shelter in the poorest quarters.

Professor Pearson has also investigated the causes of infant mortality, and the mortality which is recorded in back-to-back houses and small tenements, and here again the influence of inborn qualities is shown to be greater than preventible agencies.

Major Darwin has written much of interest on the subject of economics in relation to eugenics. Among other matters he endeavours to show that if material success in life may be taken as a standard of efficiency, danger exists from the present differential birth-rate, since the more undesirable elements propasate at a greater rate than do the more desirable. "Great poverty" he writes "and a high birth-rate inevitably tend to go hand-in-hand." "Greater wealth is found to be associated. with a lower and not with a higher birth-rate." These facts, if there are no counterbalancing forces, will result in a serious state of affairs of great nationa! importance in a comparatively short time. In this connection the influence of the death-rate, which is also differential in its effects, requires to be considered. Does it balance the undesirable position which is being created, or does it only minimise it, and thus stave off the certain creation of an inefficient race, which cannot hold its own in the great international competition, to a somewhat more distant date; and if so, how is the position to be improved? Professor Pearson emphasises the dangers which are to be apprehended from a state of affairs which results in 50 per cent of the children born being the offspring of that 25 per cent, of the poptration which constitute the least worthy elements. If the more worthy do not accept their duty to propagate, it becomes a pertinent question as to how the 
disproportionate increase of the unfit is to be prevented.

These economic considerations are emphasised further by the correlation which has been shown to exist between the wage-earning capacity of the population, pauperism, insanity and tuberculosis. Mental deficiency, and the mental state which is so unstable that environmental conditions are liable to give rise to certifiable insanity, are conditions which increasing numbers of pedigrees prove definitely to run to families, and it requires no stretch of imagination to see how poor sagacity, when combined with lack of energy, results in pauperism and a permanent low place in the social scale. Closely related to these conditions are such unfortunates as epileptics, those with immoral tendencies, the habitual criminal, the chronic tramp, the men and women who are devoid of all sense of responsibility to their families, perhaps some alcoholics and so on. We are faced with the problem that if these are inborn qualities, how far will increased wages, improved housing and sanitation, facilities for free treatment, State doles and contributions and the like improve or worsten the position.

Much more could of course be written to show that "nature" must be given first consideration in questions of racial improvement, and that inherited mental qualities are the more important factors. The practical application of acquired knowlege represents the problem which Medical Officers of Health are now called upon to accept as part of their public health functions. It is quite evident that a satisfactory and comprehensive solution is beyond the range of human ingenuity at the present time; but in many directions useful advice and action is possible, and the division of present day suggestions into more or less arbitary groups seems the best way of approaching the subject.

Environmental conditions and personal assistance.-Under this heading máy be included sanitary improvements in the broadest sense; facilities for medical treatment whether at special clinics, school clinics, or infant welfare centres, hospitals or similar institutions; direct aid for parents to assist in bringing up families; poor law assistance and the like. It has been suggested that direct aid to assist unworthy stocks to bring up children who are not likely to develop into good citizens is money badly spent, but it is not easy to see how a basis of differential treatment can be devised. The fundamental difficulty arises from the fact that no grade of society can be regarded as possessing the monopoly of brains or of producing persons who lack intelligence, and in neither class can the group with any degree of certainty-no matter what the probabilities may be-be divided into fit and unfit. The tendency at present is to support all members of the community who lack the means necessary to provide themselves or their families with the means of subsistence, or to procure medical help. The term "endowment of motherhood" which was used first by Professor Pearson nearly thirty years ago, and was then received with some scépticisn, seems now to be receiving a fuller measure of acceptance under the more modern title of "pensions for mothers"; but if such direct doles are to be productive of the greatest value to the State it would appear that such direct help should only be paid to parents of acceptable ancestry. Our social code in the present state of evolution would not accept this differentiation, and it must be left for future knowledge either to justify it, or to show that the amount of harm done to the race by indiscriminate distribution of aid is either negligible or can be minimised in some other way. In other respects State aid, such as that given by the Poor Law, undoubtedly requires immediate modification.

Improved sanitary conditions, and adequate facilities for medical treatment for all, seem absolute essentials. No deficiency in this connection should, I venture to think, be countenanced if only as a measure of selfpreservation by the more worthy. Although the absence of certain innate qualities may result in the best devised means of prolonging life and reducing human suffering being rendered nugatory among that class, it seems almost certain that if they were ignored these deficiencies combined with defective surroundings would constitute a perpetual menace to the health of the whole community. It appears to me to be certain that the best intentioned 
eugenic measures will fail if the value of environmental conditions is not properly assessed.

Questions affecting the differential deathmarriage-and birth rates.-Many of these problems affect us considerably, whilst others, of less direct interest, rely on public opinion for their acceptance or rejection and become the chief concern of statesmen for ultimate adoption. The full acceptance of many suggestions is not possible either on the grounds of public education not being sufficiently advanced, or of inadequate proof of desirability; nevertheless, they now represent matters on which we should hold a watching brief. Improved sanitation must result in all round improvement as regards the death rate. It will give those blessed with sound constitutions the best opportunity of taking advantage of their birth endowment; and although it may result in persons with defective constitutions living longer and thus increasing the numbers with hereditable defects, the possibility must be ignored in the interests of those better equipped. The arguments against measures designed to save infant life do not appeal to me, for it is surely the position that if infant mortality is high there is no certainty that the best only will survive, or that a large proportion of the better elements will not be materially injured by the conditions which play havoc with those infants of less well-endowed powers of resistance. I know of no comparisons which satisfactorily set out the relative relationship of the advantages or disadvantages in this connection which would justify acceptance of the opposite attitude.

An increase in the marriage rate among the better endowed, and incidentally of the birthrate, is expected by some to arise from the adoption of measures of assistance particularly designed to benefit that class. Among these are $(a)$ greater relief by grading the incometax or providing for better allowances for families; (b) arrangements for relieving those with large families from some of the heavy burden of local taxation, since a man with a large family requires a larger house, and thus, in addition to his voluntarily incurred heavy expenditure, he must contribute more to the rates of the district; and (c) the curtailment of the inheritance of wealth. Dysgenic effect, in two matters which may be grouped in this section is surely the result of inflicting a handicap on persons with families, such "as limiting appointments to persons "without encumbrances," and the refusal to let houses to parents with children.

Marriage Laws.-Alterations in the marriage laws again are matters which hardly affect us directly but which we cannot afford to ignore. If, in consequence of economic pressure or legal enactments, marriage is rendered a more responsible or difficult matter, the resultant dangers seem to be in the direction of increasing prostitution or illegitimacy. If rendered too easy, or if divorce is unreasonably facilitated, the tendency is-ignoring the religious aspect -for the contract to be entered into without due regard to the responsibilities which should be accepted and there might arise a real danger of domestic life and national social welfare being interfered with. In connection with divorce I must confess that the guilty party often, or both parties at times, do not appear to possess the innate qualities which it is desirable that the best citizens should possess, but whether increased or restricted freedom of the guilty party is advisable, I cannot decide. In respect to marriage, less importance should be attached to affinity than consanguinity, but the basis of consideration and of decision are obviously different; and as regards the marriage of tainted persons whether by disease or descent, or the marriage of alcoholics and the like, education of the public will probably prove more effective than legal restriction. In this relationship I may mention that at the Venereal Diseases' Clinic in the City, which is administered by St. Bartholomew's Hospital, it is proposed to open a Marriage Test Department.

The matter of legitimatising children by subsequent marriage of the parents, and the proposal to make the father of an illegitimate child more equally share the responsibility of the mother, seem desirable proposals.

Legal control.-The policy of legal control is one of surpassing interest both to the citizen and the eugenist. To the former it means State approval of restriction of liberty, and to the latter it supplies a means, if practised under adequate safeguards, for restricting, in 
some measures, the out-put of the unft. Examples of the class which enter this group are the incurable tramp who is both useless to the community and a continual cause of expense; the habitual criminal who seems unable to resist the temptation to commit petty offences, or continually offends in serious matters of a more or less associated character -this being in opposition to the isolated serious offence committed by a normal man; and persons with mental defects, either the mentally defective so-called, the epileptic, the insane, and imbeciles and idiots.

Segregation of tramps in working colonies has, been advocated, and probably it is a sound suggestion; long detention in suitable houses of control as opposed to short sentences of imprisonment has been proposed as a means of dealing with the habitual offender, and control of those with mental defects is under certain conditions now an accepted and legal measure. These proposals if put into effect, obviously would reduce the number of children born to such parents, and thus the extension of these powers is a matter of prime importance; but difficulties exist because of the want of uniformity of decision owing mainly to the lack of authoritative scientific pronouncement as to the facts on which decisions should be based. Medical Officers of Health can furnish much useful information, and it should be their duty to do so. Sterilisation will probably never be accepted by the people of this country, notwithstanding, the tendency to increased acceptance of the measure in America. Sir W. F. Mott aptly expresses the position in the senterce "When, hereditary health, as shown by longevity, fertility and mental stability in a stock is regarded as a greater asset for happiness in the family and the nation than hereditary, wealth, then will be the time for the rich and comparatively prosperous to suggest the desirability of sterilisation of the insane pauper. For no one supposes that it would be carried out in all classes."

Education -As one of the immediate practi. cal measures which can be put into operation, education of the public both young and old holds first place. It is onily by repeated insistence of the ideals of human relationship and the advantages of a healthy race in promoting human happiness and reducing human suffering that the public will be brought to think for themselves. If they once realise the value of a clean life and that domestic distress generally follows apathy in the selection of a mate, increasing numbers will act on this conviction imparted. Both in the school and at public assemblies it ought not to be impossible to impart information of an attractive and instructive nature on such subjects as the principles, of sound breeding, sex hygiene, and sex relationship, the dangers to themselves and their future families of racial poisons, the ideals of life and class relationship in relation to national patriotism and the like.

Accummulation of Facts.-In my opinion the chief opportunity which the Medical Officer of Health has for promoting the science of eugenics is in the collection of facts. It requires courage in view of the amount of routine information which now requires to be collated to suggest additions, but present routine should be carefully scrutinised and where possible, elimination should be arranged in favour of the present proposal. In the collection : of facts careful organisation is necessary. It is folly, as all will agree, for deductions to be/made on insufficient data; and if sufficient facts are available, not to give due consideration to related circumstances. It would be a great advantage if facts relating to special conditions could be collected under skilled and expert guidance. In this way special problems could be scientifically handled as affecting an area or the country as a whole. The problem to be investigated having been decided the expert in charge would so arrange that uniformity in observation and record would as nearly as possible result by defining the points to be observed and the value to be given to a recognisable variation from the fixed standard. A skilled man would not only recognise the useless observers but he would be able to sont and use his facts to greater advantage than would the observer's themselves using the same facts each in his own way. Conclusions would be sounder and policy advocated as a result would be of greater value. I should therefore be glad to see a Government statistical department created for carrying out practical investigation. work in connection with many of the 
social problems which interest us to-day. I feel sure that by this means much of the uncertainty which exists in many directions would be removed and a new interest in old problems created.

In conclusion I submit the following as a present policy for adoption by Medical Officers of Health in connection with the science of eugenics:-

(a) Every attention should be given to the improvement of environmental conditions as much in the interest of the worthy as the unworthy.

(b) The adoption of measures which will render the best medical treatment readily available for all sections of the community should be encouraged.

(c) A cautious attitude should be adopted in the recommendation of direct relief in money or lind; with a view to ensuring that at least the more worthy elements of the population shall benefit to the full from any proposal adopted, and that the effects on the less worthy shall be properly observed and recorded, particularly as to whether it encourages them in their unworthiness.

(d) State control and even segregation of persons mentally defective, using the term in its broadest sense, must be advocated, but every endeavour must be made to place mental deficiency on a scientific and uniform basis by the useful accunulation of facts.

(e). The public should be educated in the matters referred to. The education in the case of the unworthy, will be productive of but little good. It may, however, reasonably be expected that the more worthy and thoughtful members of the community will be moved to act correctly in respect of matters which they have failed so far to regard as important, and finally

(f) The opportunity which Medical Officers of Health possess in a greater degree than any other section of the community, of collecting facts, must be seized. This should be undertaken in the respect of problems selected by a competent authority on lines directed by such atthority, leaving to the same authority the duty and responsibility of drawing conclusions therefrom.

A short discussion followed the reading of Dr. Howarth's paper. Major Leonard Darwin, speaking of racial poisons, was inclined to doubt whether alcohol or syphilis ultimately affected the racial qualities of future generations; he thought there was ample ground for fighting these things without bringing in the question of racial poisons. On the question of sterilisation of the unfit, he said that he was very familiar with and sensitive to the arguments which could be urged against it, in particular the almost unsurmountable prejudice of the public; nevertheless, it would be in many cases by far the most humane thing to do. He wished that a medical man would devote himself to experimental work on methods of sterilisation, and would endeavoui. to discover whether $x$-rays did not offer the most effective and least difficult procedure. He warmly supported the plea which Dr. Howarth had made for a statistical department in the Ministry of Health to deal with social questions, and also urged that the influence of hereditary and environmental factors should be more carefully studied in the medical schools.

Dr. C. W. Saleeby urged the establishment of a permanent anthropometric department under Government auspices; indeed, he regarded such a department as a fundamental piece of structure in the Ministry of Health. He referred to some recent work carried out at the John Hopkins Hospital in the United States in which, out of a very large number of still-births, it was found that a considerable proportion-something like a quarter-were not to be explained by any known factor, syphilis and other conditions having been excluded. This suggested to his mind that there was still a great deal to learn about ante-natal conditions, in particular the dietetics of the mother.

Wimbledon Town Council have decided, after formal advertisement of the vacancy, to appoint Dr. D. A. Belilios to be medical officer of health for the borough at a salary of $£ 800$, rising to $f 1,000$ per annum. 